\title{
Atomic Spectroscopy S \\ Determination of Selenium by Platinum-coated Tungsten Coil Trap Hydride Generation-Atomic Absorption Spectrometry
}

\author{
Dilek Yildiz * \\ Mugla Sttkı Koçman University, Environmental Problems Research and Application Center, Mugla 48000, Turkey
}

Received: April 23, 2021; Revised: May 22, 2021; Accepted: May 26, 2021; Available online: May 26, 2021.

DOI: $10.46770 / A S .2021 .026$

\begin{abstract}
A highly sensitive analytical technique was developed in which gaseous hydrogen selenide generated by sodium tetrahydroborate reduction was transported and trapped on a resistively heated platinum-coated W-coil trap for in situ preconcentration. The selenium concentration was determined using hydride generation-atomic absorption spectrometry (HG-AAS). The surface of the W-coil was covered with platinum using the electrodeposition technique in the presence of $\mathrm{H}_{2}$ and $\mathrm{Ar}$. According to the results of Scanning Electron Microscopy and Energy Dispersive X-ray Spectroscopy (SEM-EDX) images, the ratio of Pt was $54.74 \%$ on the $\mathrm{W}$-coil trap surface. Various experimental conditions, such $\mathrm{NaBH}_{4}$ and hydrochloric acid concentration, and carrier gas flow rate, were optimized. In addition, the effect of the hydride-forming elements was quantitatively evaluated. The limit of detection for Se was $21.1 \mathrm{ng} / \mathrm{L}$. The proposed method was also applied to the determination of selenium in certified reference material (SRM 1640a Trace Elements in Natural Water) which showed that the analysis could be performed with a relative error of about $8 \%$. The precision of the method was evaluated and a relative standard deviation (\%RSD) lower than $10 \%$ was obtained.
\end{abstract}

\section{INTRODUCTION}

Selenium (Se) and its compounds are essential for human health, but its physiological function is changeable ${ }^{1}$ and can be toxic if taken above a certain level. As a dietary supplement, the European Food Safety Authority has published recommendations of 15-70 $\mu \mathrm{g} / \mathrm{d}$ Se intake (adequate intake, $\mathrm{AI}$ ) for humans. ${ }^{2}$ To avoid excessive intake, the Food and Agriculture Organization of the United Nations/World Health Organization has defined the upper limit of Se tolerance at $90-400 \mu \mathrm{g} / \mathrm{d}$ per person. ${ }^{3}$ Therefore, in order to determine trace $\mathrm{Se}$ in environmental and biological matrices, reliable and sensitive analytical methods are required. ${ }^{4}$

Vapor generation atomic absorption spectrometry (VG-AAS) is a sample introduction technique that converts the elements into gas phase species in three steps: (1) generation of volatile analyte species, (2) carrying volatile analyte species to the atomizer, (3) decomposition of volatile analytes and measurement of the atomic absorption response. The advantages of this technique include analyte separation from its matrix and better sensitivity due to a higher efficiency of the sample introduction. In addition, a larger sample volume can be used and thus, better detection limits can be obtained. ${ }^{5}$ There are different types of vapor generation techniques such as hydride generation (HG), cold vapor generation and photochemical vapor generation. Among them, hydride generation is the most commonly used technique since it can be applied to elements forming volatile hydrides. ${ }^{6}$ Photochemical vapor generation is based on the radical formation from the aqueous solutions containing low molecular weight carboxylic acid by exposure to UV light. This phenomenon was adapted to the determination of selenium by using photochemical vapor generation in 2003 by Sturgeon and coworkers. ${ }^{7,8}$

HG became very popular because it only requires a simple and low-cost apparatus and provides preconcentration and separation of the analyte from the sample matrix. This property results in higher sensitivity with a suppression of interferences during atomization. Another advantage is its ability to perform speciation analysis of hydride-forming elements. ${ }^{9}$ Although interferences are 
still encountered, it is easier to minimize the interferences in comparison with the techniques of graphite furnace or flame AAS. $^{10}$

High introduction of the analyte and matrix separation are obtained by reducing the analyte with $\mathrm{NaBH}_{4}$ to the corresponding hydride with a reliable and low-cost detector coupled to HGAAS. ${ }^{10,11}$ For on-line atomization with AAS, conventional quartz tubes are the most commonly used devices since they provide high sensitivity and low baseline noise. Thus, running and investment costs are low. ${ }^{12}$ Using a $\mathrm{W}$-coil as a trap is an alternative to on-line trapping and HG-AAS. A W-coil atom trap can be resistively heated by passing electricity directly through this device. While external heating is required for the quartz trap, higher heating can be achieved with a W-coil atom trap. The tungsten coil from a commercial visible tungsten lamp can be easily and economically obtained. The W-coil atom trap operates on principles similar to those of the quartz atom trap. The W-coil trap is located in the inlet arm of a conventional T-tube quartz atomizer and the temperature can be conveniently adjusted to optimized values for the collection and revolatilization stages. ${ }^{13}$

The physical and analytical tube lifetime of the bare tungsten tubes is typically about 250 firings. A smooth glassy structure is observed on the surface of the tungsten tubes, modified with platinum. Probably, a Pt-W alloy, consisting of 63.5 to 95.3 atomic percent of tungsten and exhibiting a melting point of about $2500{ }^{\circ} \mathrm{C}$, is formed on the surface of the tungsten grains. Thus, platinum is thermally stabilized (melting point of pure platinum is $1769^{\circ} \mathrm{C}$ ) and provides a permanent modification of the tungsten tube for efficient trapping of the selenium hydrides. ${ }^{14}$

In a recent study, a modular trap and atomizer device has been developed to trap Se hydride. A device consisting of a gold wire absorber was employed for Se collection. The major advantage of a modular design is that it allows easy and quick replacement of the inlet arm which acts as a trap. ${ }^{11}$ Kula et al. ${ }^{15}$ developed a new analytical technique in which gaseous hydrogen selenide generated by sodium tetrahydroborate reduction was transported and trapped in a resistively heated gold-coated W-coil atom trap for in situ preconcentration. Gold coating on the W-coil was prepared by the electrodeposition method using an organic $\mathrm{Au}$ solution. ${ }^{15}$ The capability of in situ trapping of selenium and arsenic hydrides within a bare and modified (Pd, Pt, Ir, and Re) tungsten tube atomizer was conducted by electrothermal atomic absorption spectrometry and a radiotracer technique by using ${ }^{75} \mathrm{Se}$ radionuclide. Trapping was found to have low efficiency (below 5\%) within the bare tungsten tube. Besides, modification with 100 $\mathrm{mg}$ of Pt, Ir and Re, respectively, was found to have increased the efficiency of trapping significantly. ${ }^{14}$ In a study, in order to determine tellurium, a sensitive and basic method was developed in combination with electrically heated quartz tube atomic absorption spectrometry and tellurium hydride trapping on platinum-coated tungsten coil. By using a mixture consisting of $\mathrm{Ar}$ and $\mathrm{H}_{2}$, transportation of tellurium hydride was carried out to the tungsten coil for trapping at $390{ }^{\circ} \mathrm{C}$ and releasing at $1200{ }^{\circ} \mathrm{C}$. A limit of detection (LOD, $3 \sigma$ ) of $0.08 \mathrm{ng} \mathrm{mL}^{-1}$ was calculated with $1 \mathrm{~min}$ trapping (1.5 $\mathrm{mL}$ sampling volume), and the enhancement factor was 28 compared to conventional HG-AAS. ${ }^{16}$ Barbosa et $a l .{ }^{17}$ are the prominent advocates of in situ trapping of selenium hydride on rhodium-coated tungsten coil. In addition, Ataman et al. ${ }^{18}$ reported the use of bare tungsten coil to trap bismuth hydride. Later, the use of tungsten coil to trap hydride had undergone further investigation by several groups for the determination of arsenic, ${ }^{6,19}$ selenium, ${ }^{6,15}$ bismuth, ${ }^{20}$ cadmium, ${ }^{21}$ and antimony ${ }^{22,23}$ in various samples. ${ }^{16}$

The aim of this study was to develop a sensitive analytical method for Se determination by using a W-coil for both trapping and releasing hydride species and coupling this system to HGAAS. The surface of the $\mathrm{W}$-coil was coated with platinum $(\mathrm{Pt})$ to lengthen the life-time of the W-coil. The novelty of this study is that platinum coating was used for the first time in the determination of Se by HG-AAS. Chemical hydride generation is included in the first volatilization step and is followed by trapping, revolatilization and finally atomization in an externally heated QTA where a transient AAS signal is obtained. Interference of the hydride-forming elements of $\mathrm{As}, \mathrm{Sb}, \mathrm{Sn}, \mathrm{Bi}$, and $\mathrm{Hg}$ on $\mathrm{Se}$ determination was investigated. The accuracy of the method was tested by using SRM 1640 Trace Elements in Natural Water and the analytical figures of merit were determined.

\section{EXPERIMENTAL}

Instrumentation. A hydride generation (VGA 77) atomic absorption spectrometer (Agilent Technologies 200-series), equipped with a selenium hollow cathode lamp (HCL), was used in the detection step. The lamp current was set to $10 \mathrm{~mA}$, the wavelength to $196 \mathrm{~nm}$ and the spectral band pass to $1.0 \mathrm{~nm}$. Since the peaks were very sharp, peak height absorbance was used as the basis for the measurements.

The quartz T-tube atomizer was heated externally by an airacetylene flame. The length of the horizontal arm of the quartz Ttube was $140.0 \mathrm{~mm}$, while the vertical arm was $100.0 \mathrm{~mm}$. The inner and outer diameters of the horizontal arm were 15 and 18 $\mathrm{mm}$, respectively. The inner and outer diameters of the vertical arm were 6 and $9 \mathrm{~mm}$, respectively.

For the separation of hydrogen selenide from the liquid phase, a cylindrical gas liquid separator (GLS) was employed. A mixture of $\mathrm{H}_{2}$ and $\mathrm{Ar}$ was used in the on-line atomization mode or in the collection mode. The $\mathrm{W}$-coil used for trapping was obtained from commercially available slide projector bulbs (HLX 64633, OSRAM, Munich, Germany) and placed in the inlet arm of a quartz T-tube atomizer placed $5.0 \mathrm{~cm}$ from the connection point to the horizontal arm. A variable potential power supply (TTTTECHNI-C) and a $750 \mathrm{~W}$ transformer, connected to electricity 


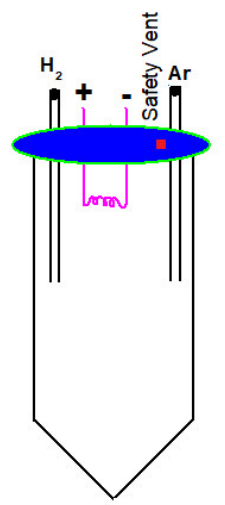

Fig. 1 The shape of the device used in platinum coating of the W-coil.
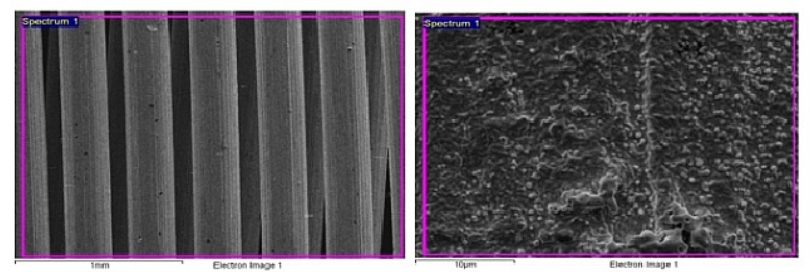

Fig. 2 SEM images of W-coil: (a) bare W-coil, (b) platinum-coated W-coil.

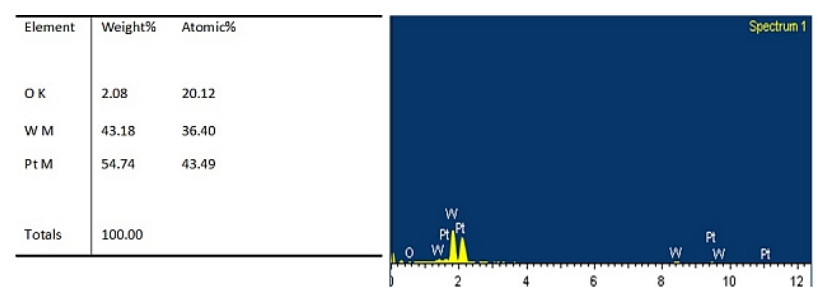

Fig. 3 EDX result of platinum-coated W-coil.

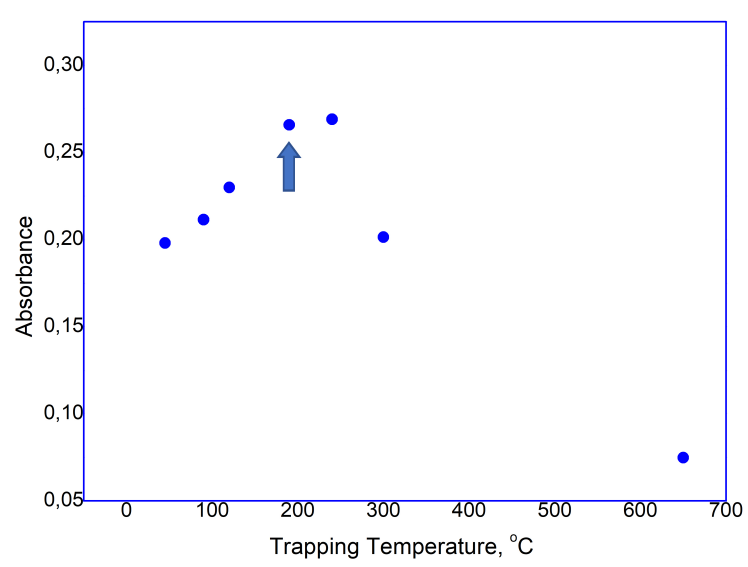

Fig. 4 Optimization of trapping temperature.

(220 V ac) through a power switch, were used to manually control the coil temperature.

Reagents. All chemicals were of analytical reagent grade and obtained from Merck (Germany). Ultra-pure quality water, produced with a Milli-Q system, was used throughout this study (Millipore, USA). For preparation of the working Se solutions, the necessary dilutions were made from their stock standard solutions: $1000 \mathrm{mg} \mathrm{L}^{-1} \mathrm{Se}$. For acidification of the analyte solutions, 37\% $(\mathrm{w} / \mathrm{w}) \mathrm{HCl}$ was used. The reductant was a $0.3 \%(\mathrm{~m} / \mathrm{v})$ solution of $\mathrm{NaBH}_{4}$ in $0.5 \%(\mathrm{~m} / \mathrm{v}) \mathrm{KOH}$, filtered after preparation, then stored frozen. For the interference studies, $1000 \mathrm{mg} \mathrm{mL}^{-1}$ stock solutions of $\mathrm{As}(\mathrm{III}), \mathrm{Sb}(\mathrm{III}), \mathrm{Sn}(\mathrm{II}), \mathrm{Bi}(\mathrm{III})$ (Fluka, Germany) and $\mathrm{Hg}$ (II) were used in the preparation of the working solutions and the blank which contains a constant Se concentration as the analyte.

Platinum coating of the W-coil. $1000 \mathrm{mg} / \mathrm{L}$ platinum in $10 \% \mathrm{HCl}$ was used as a solution (PerkinElmer, USA). A $20 \mu \mathrm{L}$ aliquot of platinum solution (PerkinElmer Pure, $1000 \mathrm{mg} / \mathrm{L}$ in $10 \% \mathrm{HCl}$ ) was manually pipetted onto the W-coil surface. The W-coil was then subjected to the following heating schedule: $3.8 \mathrm{~A}, 60 \mathrm{~s} ; 4.2$ A, $30 \mathrm{~s} ; 0$ A, $5 \mathrm{~s} ; 7.0 \mathrm{~A}, 5 \mathrm{~s}$. This process was repeated several times. During the coating process, the $\mathrm{H}_{2}$ and Ar flow rates were kept constant at $40 \mathrm{~mL} \min ^{-1}$ and $300-\mathrm{mL} \mathrm{min}^{-1}$, respectively. ${ }^{20}$ The device used during the coating process is shown in Fig. 1. The SEM (JEOL JSM-7600F instrument from MSKU Material Research Laboratory, Turkey) images were analyzed to determine the W-coil surface and the platinum coating. The SEM and EDX results of the bare W-coil and platinum-coated W-coil surfaces were obtained separately. The SEM images of bare W-coil and platinum-coated W-coil are shown in Fig. 2a and Fig. 2b, respectively. The EDX results showed that the surface of the platinum-coated W-coil was $54.74 \%$ Pt by weight (Fig. 3).

Procedure. Te measurements were performed by using both Ptcoated W-trap HGAAS and conventional HGAAS. The same atomizer (Quartz T-tube atomizer) was used with both techniques and heated externally on a stoichiometric air acetylene flame. This unit was placed in line with the burner head and then aligned with the beam pathway of the spectrometer. The $\mathrm{HCl}$ and $\mathrm{NaBH}_{4}$ concentrations were optimized in the on-line atomization mode studies using a $1.0 \mu \mathrm{g} \mathrm{L}^{-1}$ Se solution containing $7.0 \mathrm{~mol} \mathrm{~L}^{-1} \mathrm{HCl}$. The blank was $7.0 \mathrm{~mol} \mathrm{~L}^{-1} \mathrm{HCl}$ solution. The reductant and sample solutions were pumped at the flow rates of $4.95 \mathrm{~mL} \mathrm{~min}^{-1}$ and 4.55 $\mathrm{mL} \mathrm{min}^{-1}$, respectively. The generated hydrogen selenide was transported to an air-acetylene flame heated quartz T-tube. The Ptcoated W-trap in the HG-AAS procedure consisted of two steps: trapping and releasing. Optimization of the applied temperature is important to provide efficient trapping. The selenium signal increased up to $240{ }^{\circ} \mathrm{C}$, and $190^{\circ} \mathrm{C}$ was selected as optimum since at higher trapping temperatures the lifetime of the coil decreases (Fig 4). In the trapping step, the trap was resistively heated to optimum temperature $\left(190{ }^{\circ} \mathrm{C}\right)$ and hydrogen selenide was collected on the platinum-coated W-coil. During trapping, the carrier gas consisted of $475 \mathrm{~mL} \mathrm{~min}^{-1}$ Ar with $30 \mathrm{~mL} \mathrm{~min}^{-1} \mathrm{H}_{2}$.

The working range was selected from $190{ }^{\circ} \mathrm{C}$ to $1200{ }^{\circ} \mathrm{C}$ in the releasing step (Fig 5). At low temperatures, the shapes of the signals were broad and smaller in magnitude. When the 


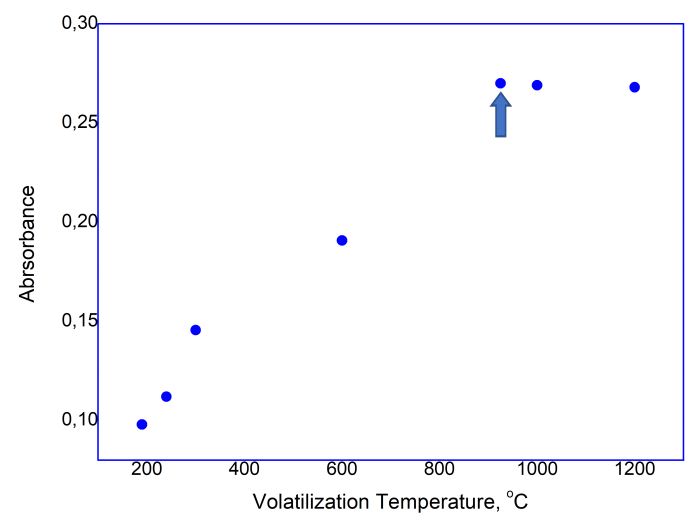

Fig. 5 Optimization of volatilization temperature.

Table 1. Optimized Analytical Parameters for the Platinum-coated Wtrap HGAAS System

\begin{tabular}{|c|c|}
\hline Analytical parameters & Optimum values \\
\hline Carrier solution & $7.0 \mathrm{~mol} \mathrm{l}^{-1} \mathrm{HCl}, 4.95 \mathrm{~mL} \mathrm{~min}^{-1}$ \\
\hline Reductant solution & $\begin{array}{l}0.3 \%(\mathrm{w} / \mathrm{v}) \mathrm{NaBH}_{4}, \text { stabilized in } 0.5 \% \\
(\mathrm{w} / \mathrm{v}) \mathrm{NaOH}, 4.95 \mathrm{~mL} \mathrm{~min}^{-1}\end{array}$ \\
\hline Sample solution & $1.0 \mu \mathrm{g} \mathrm{L}^{-1} \mathrm{Se}, 4.55 \mathrm{~mL} \mathrm{~min}^{-1}$ \\
\hline Trapping carrier gas & $475 \mathrm{~mL} \mathrm{~min}^{-1} \mathrm{Ar} ; 30 \mathrm{~mL} \mathrm{~min}^{-1} \mathrm{H}_{2}$ \\
\hline Releasing carrier gas & $475 \mathrm{~mL} \mathrm{~min}{ }^{-1} \mathrm{Ar} ; 0 \mathrm{~mL} \mathrm{~min}{ }^{-1} \mathrm{H}_{2}$ \\
\hline Trapping temperature & $190^{\circ} \mathrm{C}$ \\
\hline Releasing temperature & $925^{\circ} \mathrm{C}$ \\
\hline
\end{tabular}

temperature was increased from $925{ }^{\circ} \mathrm{C}$ to $1200{ }^{\circ} \mathrm{C}$, the signals became sharper and the signal peak height increased significantly. Therefore, $925{ }^{\circ} \mathrm{C}$ was selected as the optimum value. When the volatility temperature increased, the signal increased up to its maximum volatility efficiency, then remained constant with an increase in temperature. Temperatures higher than $925^{\circ} \mathrm{C}$ were not used to prevent deterioration of the coated $\mathrm{W}$-coil. The enriched hydride was released by increasing the Pt-coated W-coil to $925^{\circ} \mathrm{C}$ for about $1.0 \mathrm{~s}$; the flow of $\mathrm{H}_{2}$ gas was cut off from the system. Finally, the hydride was further transported to the heated quartz Ttube for atomization and a sharp, transient signal was recorded. The optimized analytical parameters for the Pt-coated W-trap HGAAS technique are listed in Table 1.

\section{RESULTS AND DISCUSSION}

Optimization of hydride generation. The acidity of the sample and the concentration of $\mathrm{NaBH}_{4}$ are important variables affecting the selenium determination. The reductant concentration was found to range from 0.10 to $0.80 \%(\mathrm{w} / \mathrm{v})$. The $\mathrm{NaBH}_{4}$ flow rate was fixed at $4.95 \mathrm{~mL} \mathrm{~min}^{-1}$ and the optimum concentration of $\mathrm{NaBH}_{4}$ was found to be $0.3 \%$ (w/v). In the preparation of the $\mathrm{NaBH}_{4}$ solutions and to obtain better stability, the dilution with $0.5 \%$ (w/v) $\mathrm{NaOH}$ was used. Only freshly prepared solutions were used. When $\mathrm{HCl}$ alone was used as the pre-reduction agent, high concentrations of $\mathrm{HCl}\left(\geq 6 \mathrm{~mol} \mathrm{~L}^{-1}\right)$ were needed to ensure quantitative results. ${ }^{24}$ The best concentration of $\mathrm{HCl}$ in the blank and the sample solutions was chosen as $7.0 \mathrm{~mol} \mathrm{~L}^{-1}$. This value kept the Se in the +4 state during the experiment and provided best sensitivity for hydride production.

Optimization of carrier gas flow rate. One of the most important variables to obtain the best trapping efficiency in terms of hydride collection in a Pt-coated W-coil was the effect of the carrier gas flow rate. The carrier gas was a mixture consisting of $\mathrm{Ar}$ and $\mathrm{H}_{2}$ in which the flow rates were optimized and fixed at $475 \mathrm{~mL} \mathrm{~min}^{-1}$ and $30 \mathrm{~mL} \mathrm{~min}^{-1}$ during the trapping step, respectively. Kratzer and Dědina ${ }^{25}$ concluded that in an environment rich in hydrogen, $\mathrm{H}_{2} \mathrm{Se}$ is formed and transported to a quartz T-tube that is externally heated for atomization. Kula et al. ${ }^{15}$ stated that $\mathrm{H}_{2}$ gas was needed in both the collection and the releasing steps. In our present study, only $\mathrm{H}_{2}$ gas was needed in the collection step. In the releasing step, the flow of $\mathrm{H}_{2}$ gas was cut off from the system since $\mathrm{H}_{2}$ gas was no longer needed. It is important to note that $\mathrm{Pt}$, as a noble metal, has a relatively high resistance to oxidation. ${ }^{26}$

The mechanism between Pt and Se is explained in the study by Buchkov et al. ${ }^{26}$ The $\mathrm{PtSe}_{2}$ films were prepared in a dual-zone gradient tube furnace, which was heated to a growth temperature of $550{ }^{\circ} \mathrm{C}$ under a $5 \% \mathrm{H}_{2} / 95 \% \mathrm{Ar}$ gas flow (high temperature zone). The $\mathrm{PtSe}_{2}$ layers were obtained by direct selenization from the Se vapor as well as by reaction with hydrogen selenide $\left(\mathrm{H}_{2} \mathrm{Se}\right)$, which is formed at high temperature with the $\mathrm{Ar} / \mathrm{H}_{2}$ gas mixture which reacts with $\mathrm{Se}$ as follows: $:^{26}$

$$
\begin{gathered}
2 \mathrm{H}_{2}+\mathrm{Se}_{2} \Leftrightarrow 2 \mathrm{H}_{2} \mathrm{Se} \quad \text { Eq. } 1 \\
\mathrm{Pt}+2 \mathrm{H}_{2} \mathrm{Se} \Leftrightarrow \mathrm{PtSe}_{2}+2 \mathrm{H}_{2} \quad \text { Eq. } 2
\end{gathered}
$$

Interference studies. The interference of $\mathrm{As}, \mathrm{Sb}, \mathrm{Sn}, \mathrm{Bi}$ and $\mathrm{Hg}$ on the Se determination was investigated because volatile types of these elements were efficiently co-produced with selenium hydride. ${ }^{11}$ No significant interferences were observed except for $\mathrm{Hg}$, which can produce severe interference in the process of hydride generation. The comparison of the interference extent in the online atomization mode and the preconcentration mode is shown in Table 2.

Table 2. Interferences of the Co-exited Hydride-forming Elements on Se Determination in the On-line Atomization Mode and in the Preconcentration

\begin{tabular}{llrrrr}
\hline \multirow{2}{*}{ Interference } & Mode & \multicolumn{3}{c}{$\begin{array}{c}\text { Recoveries } \\
\text { interference concentration }{ }^{\text {a }}\left(\mu \mathbf{g ~ L}^{-1}\right)\end{array}$} \\
\cline { 3 - 6 } & & \multicolumn{1}{c}{$\begin{array}{c}10 \\
\text { in }\end{array}$} \\
\hline \multirow{2}{*}{ As } & Preconcentration & $97 \pm 6$ & $93 \pm 4$ & $90 \pm 5$ & $83 \pm 8$ \\
& On-line & $98 \pm 5$ & $95 \pm 5$ & $93 \pm 6$ & $90 \pm 4$ \\
Sb & Preconcentration & $100 \pm 3$ & $104 \pm 4$ & $107 \pm 2$ & $110 \pm 5$ \\
& On-line & $101 \pm 1$ & $104 \pm 2$ & $109 \pm 2$ & $114 \pm 3$ \\
Sn & Preconcentration & $100 \pm 2$ & $107 \pm 5$ & $112 \pm 4$ & $117 \pm 9$ \\
& On-line & $100 \pm 3$ & $110 \pm 3$ & $114 \pm 4$ & $123 \pm 3$ \\
Bi & Preconcentration & $99 \pm 9$ & $96 \pm 5$ & $91 \pm 8$ & $86 \pm 3$ \\
& On-line & $105 \pm 5$ & $103 \pm 4$ & $100 \pm 6$ & $96 \pm 3$ \\
Hg & Preconcentration & $102 \pm 7$ & $126 \pm 5$ & $143 \pm 6$ & $165 \pm 5$ \\
& On-line & $100 \pm 4$ & $112 \pm 3$ & $109 \pm 3$ & $106 \pm 4$ \\
\hline
\end{tabular}

${ }^{\mathrm{a}}$ Analyte concentration of $1 \mu \mathrm{g} \mathrm{L}{ }^{-1}$. 
Table 3. The reported LOD Values in Similar Studies

\begin{tabular}{lll}
\hline Techniques & LOD, $\mathbf{n g ~ L}^{-1}$ & Ref. \\
\hline Rh-coated W-coil-trap-ETA & 50 & {$[17]$} \\
Au-coated W-coil-trap-HG-AAS & 39 & {$[15]$} \\
Purge-and-trap collection & 1300 & {$[27]$} \\
A trap-and-atomizer device with & 7 & {$[11]$} \\
a gold absorber & & \\
Collection on gold wire-AFS & 5 & {$[28]$} \\
Pt-coated W-coil-trap-HG-AAS & 21.09 & This study \\
HG-AAS & 205.1 & This study \\
\hline
\end{tabular}

Analytical figures of merit. After the optimization step, a calibration graph was drawn for Se by using the Pt-coated W-trap HG-AAS system. Se was studied in the range of $0.05-10.0 \mu \mathrm{g} \mathrm{L}^{-1}$. The calibration plot was linear from 0.25 to $10 \mu \mathrm{g} \mathrm{L}^{-1}$ for Pt-coated W-coil trap HG-AAS measurements.

The limit of detection (LOD), limit of quantitation (LOQ) and relative standard deviation (RSD) values of Se for the Pt-coated W-trap HG-AAS system were calculated by using peak height of the absorbance signal. They were calculated from 11 replicate measurements of the smallest concentration for Se. The RSD value was calculated for 11 replicate measurements of the lowest concentration in the linear calibration range.

The LODs value of several studies published in recent years for the determination of Se is given in Table 3. As can be seen from Table 3, the LOD of the proposed method is comparable to Rhcoated W-coil-trap-ETA, ${ }^{22}$ Au-coated W-coil-trap-HGAAS ${ }^{13}$ and better than those obtained by purge-and-trap collection. ${ }^{27}$ In the study by Guo and Guo; ${ }^{28}$ the Pt wire was investigated by testing the $\mathrm{SeH}_{2}$ collection efficiencies. The Pt wire trapped $\mathrm{SeH}_{2}$, but it could not be released from the Pt wire surface. However, the present study proved that $\mathrm{SeH}_{2}$ was successfully trapped and released on the Pt-coated W-coil surface which is an important finding added to the literature.

Accuracy test and real sample analysis. The accuracy of the method was evaluated by analyzing standard reference materials (SRM 1640a Trace Elements in Natural Water) and a relative error of $7.30 \%$ was found. Stock SRM solutions were diluted 200 -fold. It was found that there was a good agreement between certified value $\left(20.13 \pm 0.17 \mu \mathrm{g} \mathrm{L}^{-1}\right)$ and found value $\left(21.60 \pm 0.31 \mu \mathrm{g} \mathrm{L}^{-1}\right.$ for SRM 1640a under the optimum conditions using Pt-coated Wcoil atom trap HG-AAS method. This method was applied to the determination of $\mathrm{Se}$ in three drinking waters $(0.30 \pm 0.02$, $0.65 \pm 0.10$, and $0.59 \pm 0.05 \mu \mathrm{g} \mathrm{L}^{-1}$ ) and is also suitable for the determination of ultra-trace Se in environmental and biological samples.

\section{CONCLUSIONS}

A new and simple method has been developed for the determination of selenium and results in a low $\operatorname{LOD}\left(21.1 \mathrm{ng} \mathrm{L}^{-1}\right)$, wide linear range and good anti-interference ability for hydride- forming elements. The lifetime of an individual $\mathrm{W}$-coil is an important parameter in W-coil studies. Since oxidation of the -coil takes place, the sensitivity of the system declines with time. In optimum conditions, the Pt-coated W-coil can be used at least 300 times. The structure of the Pt-coated W-coil trap is quite simple and inexpensive with the advantage that as a noble metal, $\mathrm{Pt}$ has relatively high resistance to oxidation. Therefore, the expensive $\mathrm{H}_{2}$ gas is not needed in the releasing step. The proposed Pt-coated Wcoil trap method is a good and low-cost alternative for Se determination in comparison to using the relatively expensive instruments such as ICP-MS, ICP-OES and AFS.

\section{AUTHOR INFORMATION}

\section{Corresponding Author}

* D. Yildiz

Email address: dyildiz@mu.edu.tr

Notes

The authors declare no competing financial interest.

\section{REFERENCES}

1. J. Kratzer, S. Musil, and J. Dědina, J. Anal. At. Spectrom., 2019, 34, 193-202. https://doi.org/10.1039/c8ja00312b

2. European Food Safety Authority (EFSA). EFSA J. 2014, 12, 3846.

3. FAO/WHO. Vitamin and mineral requirements in human nutrition, 2nd ed.; World Health Organization: Geneva, Switzerland, 2004; pp 194-216.

4. M. Liu, J. Liu, X. Mao, X. Na, L. Ding, and Y. Qian, Anal. Chem. 2020, 92, 7257- 7264.

https://dx.doi.org/10.1021/acs.analchem.0c00878

5. X-P. Yan and Z-M. Ni, Anal Chim Acta. 1994, 291, 89-105. https://doi.org/10.1016/0003-2670(94)85130-1

6. S. S. de Souza, D. Santos, F. J. Krug, and F. Barbosa, Talanta, 2007, 73, 451-457. https://doi.org/10.1016/j.talanta.2007.04.031

7. X. Guo, R. E. Sturgeon, Z. Mester, and G. J. Gardner, Appl. Organomet. Chem., 2003, 17, 575-579. https://doi.org/10.1002/aoc.473

8. X. Guo, R. E. Sturgeon, Z. Mester, and G. J. Gardner, Anal. Chem. 2003, 75, 2092-2099. https://doi.org/10.1021/ac020695h

9. A. R. Kumar and P. Riyazuddin, Int. J. Environ. Anal. Chem. 2007, 87, 469-500. https://doi.org/10.1080/03067310601170415

10. J. Dedina and D.L.Tsalev, Hydride Generation Atomic Absorption Spectrometry, Wiley, Chichester, 1995.

11. I. Machado, D. Vaněk, S. Musil, M. Pistón, J. Dědina, and J. Kratzer, J. Anal. At. Spectrom. 2020, 35, 107-116. https://doi.org/10.1039/c9ja00290a

12. J. Dědina, Spectrochim Acta B, 2007, 62, 846-872. https://doi.org/10.1016/j.sab.2007.05.002

13. O. Y. Ataman, Spectrochim Acta B, 2008, 63, 825-834. https://doi.org/10.1016/j.sab.2008.03.013 
14. B. Docekal and P. Marek, J. Anal. At. Spectrom., 2001, 16, 831-837. https://doi.org/10.1039/b101841h

15. I. Kula, Y. Arslan, S. Bakırdere, and O. Y. Ataman, Spectrochim. Acta B, 2008, 63, 856-860.

https://doi.org/10.1016/j.sab.2008.03.020

16. M. Xi, R. Liu, P. Wu, K. Xu, X. Hou and Y. Lv, Microchem. J. 2010, 95, 320-325. https://doi.org/10.1016/j.microc.2010.01.009

17. F. Barbosa, S. S. de Souza, and F. J. Krug, J. Anal. At. Spectrom., 2002, 17, 382-388. https://doi.org/10.1039/b111129a

18. O. Cankur, N. Ertas, and O.Y. Ataman, J. Anal. At. Spectrom., 2002, 17, 603-609. https://doi.org/10.1039/B201365G

19. R. Liu, P. Wu, M. Y. Xi, K. L. Xu, and Y. Lv, Talanta, 2009, 78, 885-890. https://doi.org/10.1016/j.talanta.2008.12.067

20. R. Liu, P. Wu, K. L. Xu, Y. Lv, and X. D. Hou, Spectrochim. Acta. B, 2008, 63, 704-709. https://doi.org/10.1016/j.sab.2008.03.010

21. O. Cankur and O.Y. Ataman, J. Anal. At. Spectrom., 2007, 22, 791799. https://doi.org/10.1039/b603489f
22. O. Alp and N. Ertas, J. Anal. At. Spectrom., 2008, 23, 976-980. https://doi.org/10.1039/b801451e

23. S. Titretir, E. Kenduezler, Y. Arslan, I. Kula, S. Bakirdere, and O.Y. Ataman, Spectrochim. Acta. B, 2008, 63, 875-879. https://doi.org/10.1016/j.sab.2008.03.021

24. M. Gallignani, M. Valero, M.R. Brunetto, J. L. Burguera, M. Burguera, and Y. Petit de Pena, 2000, Talanta, 52, 1015-1024. https:// doi:10.1016/s0039-9140(00)00438-0.

25. J. Kratzer and J. Dědina, Anal. Bioanal. Chem., 2007, 388, 793-800. https://doi:10.1007/s00216-006-1048-3

26. K. Buchkov, D. Dimitrov, J. Mickovski, C. Dikov, E. Goovaerts, D. Petrova, and V. Marinova, J. Phys. Conf. Ser., 2020, 1492, 012122. https://doi.org/10.1088/1742-6596/1492/1/012022

27. I. Ueta, D. Kato, and M. Nagao, Int. J. Environ. Anal. Chem., 2020, 1, 1-7. https://doi.org/10.1080/03067319.2020.1839061

28. X.-M. Guo and X-W. Guo, J. Anal. At. Spectrom., 2001, 16, 14141418. https://doi.org/10.1039/b105737p 